\title{
Correction to: Barriers to postpartum follow-up of mothers with gestational diabetes mellitus and its implications: a mixed method study
}

\author{
Ninu P. Mathew ${ }^{1}$ (D $\cdot$ Arathi P. Rao ${ }^{1} \cdot$ Prakash Narayanan $^{1}$
}

Published online: 22 July 2021

(c) Research Society for Study of Diabetes in India 2021

Correction to: International Journal of Diabetes in Developing Countries (2021) 41:127-135 https://doi.org/10.1007/s13410-020-00853-0

The corresponding Author of this paper is Arathi P. Rao.

Publisher's note Springer Nature remains neutral with regard to jurisdictional claims in published maps and institutional affiliations.

The original article can be found online at https://doi.org/10.1007/ s13410-020-00853-0.

Arathi P. Rao

arathimph@gmail.com

1 Prasanna School of Public Health, Manipal Academy of Higher Education, Manipal, Udupi, Karnataka 576104, India 